Preprint, the final version, of the article that has been transferred to the journal's production team.

To cite this article: Ginzarly, M., Pereira Roders, A., \& Teller, J. (2018). Mapping historic urban landscape values through social media. Journal of cultural heritage.

DOI: $10.1016 /$ j.culher.2018.10.002

\title{
Mapping historic urban landscape values through social media
}

\begin{abstract}
Social media provides big data for researchers to perform real-time analytics, as digital ethnographers, on what places and attributes people value in the historic urban landscapes they live or visit, enough to share with their social network. However, the use of these data to further our knowledge on heritage and their values, or to support heritage planning and management is still very limited. This article proposes a methodology for the analysis of viewpoints locationview scenes-tags data for photos posted on Flickr to provide insights into all facets of the perceived landscape character that identifies people-centered heritage at the city level. The analysis visualizes convergence and divergence between locals' and tourists' preferences. It also reveals heritage concerns in the context of daily-life practices and everyday landscape, as well as political and religious concerns in post-conflict areas. Additionally, the analysis questions the limits of heritage areas and categories used for identifying cultural values. Results showed that the different analyses complement one another to eventually provide insights into everyday encounters with the historic urban landscape. They also show the difference between experts' and users' documentation and characterization languages when defining heritage. When the first apply domain-specific classification models, the latter express personal reflections without following a specific hierarchy or a closed categorical system. It is believed that the outcome can help heritage scholars to further our understanding for the diversity of heritage places and attributes, as well as, heritage professionals, to inform decision-making processes in heritage planning and management on both experts' and users' understanding of heritage.
\end{abstract}

Keywords: Historic Urban Landscape, Social media, Flickr, Cultural heritage, everyday landscape.

\section{Introduction}

The long debate on the conservation of urban heritage at the international and European level over the last century is gradually changing practices from a mono-disciplinary into an integrated approach that endorses community engagement. At the same time, it has extended conservation to the ordinary landscapes and daily-life heritage along with the exceptional landscapes $[1,2,3,4,5,6]$. Urban heritage is now recognized as a social construct that changes over time and space in response to the different social, economic, and political processes. The conservation of urban heritage is no more solely focused on the protection of historic assets, but also, on the management of change at the city level [7,8,9]. The 2011 UNESCO Recommendation on the Historic Urban Landscape (HUL) [6] proposes the application of an 
holistic socially inclusive approach that endorses community engagement and acknowledges the plurality and diversity of urban heritage and its capacity to continuity and change over time. The HUL is both an approach and a new understanding of the historic environment. As a definition, The HUL is the complex layering of cultural and natural values and attributes that contribute to the identity and sense of a place, or genius loci [6,10]. UNESCO [6] called for the implementation of traditional and innovative tools to ensure public participation and grasp the range of cultural values attributed by the different stakeholders as to prioritize actions and inform decision making.

Social media has been acknowledged by many cultural heritage professionals and scholars as a tool for participatory praxis, that would enable a variety of encounters and a crossdialogue between different stakeholders $[11,12,13,14,15,16,17]$, allowing multivocal heritage narrative to confront controversy over cultural heritage. It provides big data that communicates valued aspects of the urban landscape, daily practices, personal experiences, and people's construct and definition of heritage $[16,18,19]$. Social media reconsiders our understanding of cultural heritage by providing a community-based platform for communicating users' interaction with cultural heritage in their personal context and in association with collective memory and identity of place [16]. Accordingly, it allows users to become more of an active co-creator than a passive receiver in the cultural heritage realm. Social media has become an essential constituent to crowdsourcing. The latter involves cultural heritage institutions soliciting contributions from online communities. Many museums in the US, Europe, Australia, and New Zealand are now exploring the potential of crowdsourcing and are using social media to generate a culture of participation around their digital collections and services. The participation may occur in two ways. Either the users upload and share their own heritage related images and stories to a site, or they post their comments about a specific heritage related item on the site [17]. Although the digitization of cultural heritage has made it polyvocal instead of being dependent on experts, Taylor \& Gibson [20] have argued that in some cases the decision on what heritage is and implications on public values have not been based on appropriation but on consumption. This fact reinforces hegemony instead of empowering the democratization of heritage. Accordingly, a bottom-up approach should be applied to manage conflicts of interests between locals, experts, and politicians to reach maximum consensus on heritage related decisions.

Although the role of social media in providing new techniques for community engagement has been acknowledged, its usage is still very limited and not fully explored within 
the context of urban cultural heritage conservation. This paper recognizes the potential contribution of user-generated content engendered by social media services to cultural heritage management. It deliberates on the use of social media in enabling inclusiveness and empowering public participation in the urban management process. Inclusion is a key value in the implementation of the New Urban Agenda and the achievement of sustainable development goals, including Goal 11 that stresses on the need "to protect and safeguard the world's cultural and natural heritage" to "make our cities inclusive, safe, resilient and sustainable" [21,22]. This paper argues that social media metadata including photos, user-generated tags, commentaries, spatial data, and personal data of the user (age, gender, and profession) provide new tools to the understanding of the rationale and intuition of the users, and that methods that rely on these data could complement traditional survey methods to the characterization of the historic urban landscape and the range of heritage significance associated with it in the context of daily practices and user-environment interaction. This inquiry mainly questions the limits of heritage areas and closed categories used for the identification of cultural values. It also visualizes convergence and divergence between locals' and tourists' landscape preferences. Moreover, it reveals the intertwining political and religious affiliations and heritage values in the postconflict city. It is believed that the provided knowledge will improve our understanding of people-centered heritage and will help to bridge the gap between experts' and users' definition of heritage at the city scale as to eventually inform decision making.

More recently, different methodological tools that rely on social media data such as geotagged tweets, digital footprints, and photos on Flickr have been developed to visualize specific behavioural patterns and landscape perceptions, and to interpret different types of interactions between users and their environment. However, most of these studies rely mainly on the processing of geolocation data and analysis of tags. The investigation of the scenery depicted in photos posted on social media is limited to few studies and it is not yet being addressed in an holistic comprehensive approach that could serve heritage conservation. The main contribution of this study is that it proposes a framework for analyzing the viewpoint (vantage point) location, view scene (the sight depicted on the photo), and tags metadata of photos posted on Flickr in order to elicit heritage significance, its attributes (what) and values (why). First, the spatial distribution of photos is visualized to differentiate between the most and least preferred zones in the study area. Second, a classification model for clustering photos by view scene is proposed to elucidate the heritage attributes that are depicted in the range of photos. Finally, tags are evaluated to determine heritage significance through unveiling tags patterns and the range of activities, feelings, and expressions that are associated with the 
different places in the city. The combination of these analyses encompasses the identification of landscape preference to provide insights into all facets of the perceived landscape character that identify people's common heritage and shared identity

\section{Related Research}

A diversity of methods has been proposed to visualize specific behavioural patterns and landscape perceptions based on data from web services like Twitter, Flickr, google maps, and google earth. These case studies vary in size from the scale of the square to the continental scale. Each addresses explicitly or implicitly specific heritage assets and/or cultural values generated from the reciprocal relation between landscape and users (Table 1). For instance, Girardin et al. [23] used digital footprints that are generated by mobile phones using Flickr to quantify the impact of a public event on the distribution of visitors and on the attractiveness of urban space. Frias-Martinez et al. [24] used georeferenced twitter messages to identify land uses and urban points of interest, mainly to determine activities that are most common in an urban area and landmarks. Stefanidis et al. [25] used location and time data generated by Twitter to trace hotspots in different cities. The aim was to relate specific events (religious and political) to spaces and investigate how they contribute to the emergence of new hotspots in the city. GIS methods that rely on websites that are based on google maps were applied to identify public lands values and examine the association between mapped values and public land types [26]. Additionally, Dunkel [27] analyzed photos locations and tags posted on Flickr for three world regions and 12 study areas to visualize landscape perception. García-Palomares et al. [28] assessed the spatial distribution and density of Geotagged photos on Panoramio for eight major European cities to differentiate between tourists' and residents' hotspots and to identify main tourists attractions, and Zanten et al. [29] evaluated spatial data, text, and hashtags of three social media platforms: Panoramio, Flickr, and Instagram to quantify landscape values on a continental scale. Moreover, the use of tracking technologies in tourism research has been growing in recent years [30]. For instance, McKercher et al. [31] used GPS tracking data loggers and GIS analysis to compare the spatial and time-space behavioural patterns of first-time and repeat visitors to Hong Kong, and others have investigated the spacetime activities of visitors at destinations [32,33]. Motivations for photos tagging and information revealed by tags and folksonomy have been also widely investigated by scholars $[34,45,36]$. However, it has been argued that analyses of photos based on texts such as tags, titles, and comments and geographical location do not necessarily describe the view scene and 
the aspects of the environment that are actually depicted in the photo [37,38,39]. Accordingly, our inquiry borrows from the methodological and analytical frameworks applied in these studies but goes further in the analysis to investigate the scenery that is depicted in the sum of photos.

\begin{tabular}{|l|l|l|}
\hline Authors, Year & Scale & Implications for cultural heritage \\
\hline Zanten et al. [29] & Continental scale & $\begin{array}{l}\text { Quantifies landscape's aesthetic and recreation values in relation } \\
\text { to specific context variables (socioeconomic, density, and } \\
\text { cultural) and landscape features. }\end{array}$ \\
\hline $\begin{array}{l}\text { Frias-Martinez et } \\
\text { al. [24] }\end{array}$ & $\begin{array}{l}\text { Cighlights tangible (landmarks) and intangible attributes } \\
\text { (activities like leisure, business, and nightlife) in the context of } \\
\text { user-environment interaction. }\end{array}$ \\
\hline Dunkel [27] & City scale & $\begin{array}{l}\text { Highlights tangible (known places, landmarks, elements) and } \\
\text { intangible (events, feelings, and activities) attributes that } \\
\text { influence landscape perception. }\end{array}$ \\
\hline $\begin{array}{l}\text { García-Palomares } \\
\text { et al. [28] }\end{array}$ & $\begin{array}{l}\text { Identifies differences and similarities between tourists and locals } \\
\text { density and distribution in the city and identifies the main visual } \\
\text { attractions. }\end{array}$ \\
\hline Brown et al. [26] & $\begin{array}{l}\text { Public lands at the city } \\
\text { scale }\end{array}$ & $\begin{array}{l}\text { Highlights the range of values that could be ascribed to a tangible } \\
\text { asset (public lands), and assesses values in relation to the } \\
\text { characteristics of the tangible asset. }\end{array}$ \\
\hline $\begin{array}{l}\text { Stefanidis et al. } \\
\text { [25] }\end{array}$ & $\begin{array}{l}\text { Public squares at the city } \\
\text { scale }\end{array}$ & $\begin{array}{l}\text { Helps to understand how an emerging intangible asset (a } \\
\text { political event) would promote new cultural values to a tangible } \\
\text { asset (a public square). }\end{array}$ \\
\hline Girardin et al. [23] & $\begin{array}{l}\text { Project scale: a public } \\
\text { space and its surrounding }\end{array}$ & $\begin{array}{l}\text { Investigates the influence of an intangible heritage asset- a } \\
\text { cultural event related to a public art project- on people's } \\
\text { behaviour and perception. }\end{array}$ \\
\hline
\end{tabular}

Table 1: summary of the implication of case studies that used web services data for cultural heritage.

The investigation of photos' depicted scenery is still not fully explored. It has been limited to landmarks, iconic images, and representative photos eliminating a lot of photos that may embed important knowledge and aspects of the context. For instance, T.L. \& D. A. [40] applied a foreground/background segmentation method to analyze 13 worldwide recognizable landmarks' photos on Flickr to rank iconic representative images of landmarks. Kennedy et al. [41] applied a location-tag-vision driven approach to detect representative tags and views of landmarks for arbitrary areas in the world. The first method solely focuses on the visual representation of images, and the second focuses on extracting visual features of tags eliminating the ones that are related to other aspects of the environment that remain important to the understanding of the context like feelings, activities, expressions and so forth. Today, many heritage sites and institutions are investing in mobile apps with the goal of interpreting cultural heritage to the general public, suggesting places and touristic trails based on the user's interests and location, and in some cases providing virtual exhibitions [42]. However, there is 
still no clear evidence about the effectiveness of these apps and their potential in offering meaningful learning experiences [43;44].

Existing studies have not yet applied a comprehensive approach to the analysis of viewpoint location, view scene, and tag metadata. Instead, more attention was given to the analysis of geographical information and tags, and the view scene analyses have addressed specific aspects of the built environment and attraction points. This study tests the use of social media in the service of urban management. It addresses the city as a whole. It goes beyond well-maintained areas to also investigate ordinary and even deteriorated landscapes. Our method gathers all the data for the sum of photos posted on Flickr for Tripoli, Lebanon, visualizes hot and cold areas in the city, analyzes tags, and classifies photos according to their content to reveal landscape preferences, activities, practices, expressions, and values attributed by the public to the historic urban landscape. The outcome would help experts to identify heritage significance, its attributes and values that are not yet recognized. Moreover, it would help differentiate between the diverse interests and interpretations of heritage significance, among the different stakeholders in the city namely the locals, the tourists, and the experts.

\section{Conceptual Framework}

The framework of this study is built around three key concepts in the context of cultural heritage and social media (Fig. 1): (1) social media is a platform for people-centered heritage [19]; (2) photo sharing on social media is a form of cultural expression [45]; and (3) social media enables the creation of shared heritage and collective memory [46].

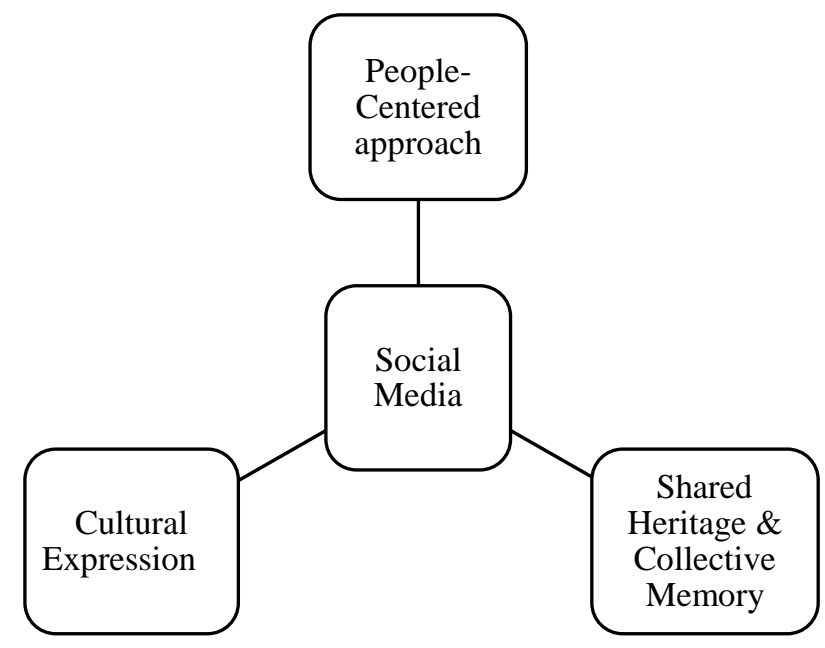

Fig. 1: Conceptual Framework. 
Collective memory is a social construct of past lived experience [47]. It is "a continuous current of thought, of a continuity that is by no means artificial, because it conserves nothing from the past except the parts which still live, or are capable of living in the conscience of the group"[47: 132]. Collective memory is a form of identity, continuity, and meaning transmission from the historical past of a community [48,47]. It enables individuals to share memories of events, places, cultural practices, and ways of life within collectives [49]. Collective memory is the foundation of a society's values. The HUL approach to heritage conservation stressed that conservation practices should respond to communities' needs for development and adaptation to change while retaining the features and values linked to their collective memory [6,50]. Cultural expressions result from the creativity of individuals and societies and are represented in manifold ways, like symbolic meaning, artistic dimension and cultural values that originate from or express cultural identities, and are part of a particular community's collective heritage. Cultural expressions could be conveyed through cultural activities or specific attributes, such as dance, song, or woodcarving [51,52]. Cultural expressions are presented through media as varied as photography, festivals, and exhibitions, and they are manifested informally in the course of everyday life [51]. A society's values and collective memory and the way they are expressed contribute to its cultural heritage [53]. Communities have become the focus of national and international conventions and policies calling for the application of people-centered approach to urban management [54]. This approach is supported by engaging local people and reinforcing their ability to participate meaningfully in the process of decision making as to conserve their collective memory and identity and enhance the liveability of cities $[55,53,56]$.

A photo is part of individuals' memory, narrative, and identity [45]. When photos are posted for public viewing on social media they play a role in the creation of a collective narrative and memory among common places, social practices, and activities that shape daily life. In this context, social media provides a new medium for the construction of continuous memory communities that represent the changes that occur through time to heritage assets and reflect the dynamic expression of contemporary identity [19]. Such a knowledge could provide insights into the multiple identities coexisting in a specific context, like national, cultural, linguistic, and religious identity [57]. These multiple identities are not only related to religious affiliation but also to economic, political, social class and many other assets [57]. Annotating photos with tags is a cognitive processing that reflects the users' interests and perception because tags encompass the verbal expression of the visible content of photos to include 
personal reflections, sentiments, and thoughts [36,46,35]. Tagging might be characterized as an act of sense-making, so shared tags are a form of collective meaning [46]. In this context, posting photos, sharing and annotating them with labels is a form of cultural expression in which users determine what is considered cultural. Therefore, the analysis of these metadata contributes to the understanding of the public interpretation of heritage and to the identification of the heritage by appropriation. The latter emerges through use and appears as a distinctive support of shared places and sense of belonging in everyday landscapes [58,59].

\section{Method}

The method applied for the analysis of photos was based on a bottom-up approach that attempts to analyze data relationships to gain a fundamental understanding of people-centered heritage, and then infer insights into every-day encounters with the historic urban landscape (Fig. 2). It analysed data collected from Flickr, one of the oldest social media platforms that has been widely used in environmental research [60,61]. Using the Flickr API (Application Programming Interface) documentation, data for Tripoli, Lebanon from 2003 to 2016 were retrieved. The total number of published photos in this period is 2888 . The sum of data includes: photos, photo Id, the real name of users, time (time taken, time posted), URL, tags, titles, locality, and geolocation (longitude, latitude). Afterwards, photos that were not geo-localized by the user, their geographical location was assigned manually. The data analysis process consisted of three interweaved steps. First, the geographical data was processed, then photos' content and tags were successively analyzed.

\section{Data Retrieval}

API documentation : photos, geolocation, tags.

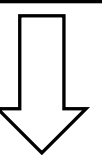

Fundamental understanding of people-centered heritage: individuals/flickr community

Processing of geolocation data \& classification of photos by content.

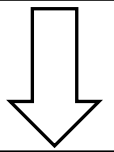

Insight on everyday encounters with the historic urban landscape

Analysis of tags and a relational assessment of results from the analyses of spatial data, tags, and content.

Fig. 2: A bottom-up approach to the characterization of the HUL. 


\subsection{Analysis of viewpoints location}

The study covered Tripoli and El-Mina municipal boundaries with a total surface area of about $26 \mathrm{Km}^{2}$. An automatic analysis of viewpoints geographical information was conducted. First, photos were assembled by photographer. Afterwards, photos of the same location taken by the same photographer were combined into one to prevent some users from dominating the final results. Accordingly, the number of analyzed photos is 1320 and their date range is from 2003 to 2016. The first reading started by differentiating between locals and tourists through investigating users' real name and country. Then, the geographical information of photos in correlation with the nationality of users' information was imported to ArcGIS to visualize the density and spatial distribution of photos, and to differentiate between locals and tourists preferences.

\subsection{Analysis of view scenes (depicted scenery)}

Each photo was assembled with its Id and URL data. All the retrieved photos were kept in one document and each was labelled according to its Id to facilitate the aggregation of photos later on. An expert-based classification model was proposed to cluster photos based on the dominant feature of the scene. It consists of two main categories tangible and intangible, and different sub-categories. This classification borrows from UNESCO's proposed documentation process of the historic urban landscape for a comprehensive landscape character identification $[6,39]$. The integrated multi-dimensional approach to the analysis and characterization of the landscape was popularized by McHarg in 1969 [62]. The approach is based on the concept of layering. It considers the relationship between many factors in a given area be it historic, scenic, natural, or residential, then all the layers are overlaid to formulate a deep understanding of an area before taking any urban planning decision [62]. The classification model was tested with two other experts. A photo that is depicting a tangible asset of the city could fall into one of these sub-categories, urban scenery, landscape scenery (context/setting), form, buildings/monuments, details, and natural features. Photos that are depicting an intangible asset could be related to practices, expressions, activities, or knowledge. Photos' Id was used as a reference while retrieving and grouping them. Subsequently, we started to navigate through the photos to deeply investigate what the scenes actually depict. First, we looked at the most frequent sceneries and analyzed results in relation to the outcome of viewpoints location analysis to see whether results are similar or complementary. Afterwards, we started to 
investigate each category separately to reveal additional information that is not detected in previous analyses.

\subsection{Analysis of Tags}

Tags were assessed through a quantitative and a categorical analysis. The first is automatic, while the second is expert-based. The quantitative analysis was meant to show the most and least used tags in the sum of photos and to help identify tags patterns. The categorical analysis sought to reveal how the users refer to the different assets of the historic urban landscape and attribute diverse cultural values to them, and how they relate certain activities, social practices, and meanings to places. The data was imported to RGui and an association analysis followed by a latent semantic analysis for multidimensional scaling (MDS) were conducted. The statistical analyses used the R packages arules and LSAfun to generate frequent tag-sets and plots on semantic space. The method combines both general-to-specific and specific-to-general strategies. In the first, pairs of frequent tags are merged to obtain candidate tag-sets. In the second, tag-sets are investigated to give a general reading of results. The terms Tripoli, Lebanon, El-Mina, and Middle East were not included in the analysis because they refer to the location of the study area, and they are mentioned in most photos.

Firstly, two levels of frequent tag-sets were generated. The first level consists of two tags and the second level includes three tags that are associated together in pictures for more than 10 times. The results were translated into a matrix that shows the association between tags. Subsequently, the generated results were used to provide two and three-dimensional visualization of nearest semantics. Afterwards, a categorical analysis differentiated between tags that have tangible or intangible semantics. The aim was to understand the first through the latter. Terms that are associated with a tangible or intangible heritage attribute were extracted. The aim was to highlight how users refer to heritage assets and whether they relate tangible and intangible attributes or not. Accordingly, tags that refer to an intangible attribute like activities, expressions, knowledge, or practices were extracted with their embedded geographical information. Examples of tangible tags include: street, castle, window, and river. As for intangible tags, they include: tradition, working, shopping, and medieval. Afterwards, a tag clouds map was generated using ArcGIS. Every tag was given a weight that is symbolized by font size according to its frequency. It is believed that the outcome would help relating activities, feelings, and practices to places and would provide an insight into the userenvironment relationship. 


\section{Results}

\subsection{Processing of geolocation data}

The number of users is 410 of which $51 \%$ are tourists and $49 \%$ are locals. $62 \%$ of photos are posted by tourists and $38 \%$ are posted by locals. So tourists posted more photos than locals. Most users posted between 1 and 5 photos and around 2\% of tourists posted more than 20 photos. The peak of the number of photos posted was in 2011, then it decreased dramatically in 2012 (Fig. 3). This change could be linked to the emergence of new photo-sharing apps like Instagram that received significant popularity by less than two years after its launch, especially when it was released for Android phones in 2012. This decrease may also be linked to local circumstances. Indeed, on a geopolitical level, Tripoli is considered as a major gateway to Syria as it is only around $38 \mathrm{~km}$ away from the Syrian border. Influenced by the Syrian crisis that started in March 2011, Tripoli has suffered from security issues between late 2011 and late 2013. During this period, Tripoli was considered as a microcosm of Syria's war in Lebanon, and a conflict took place between two neighbourhoods, on the North-West of the historic core, representing both sides of the conflict in Syria [63]. The city was then marginalized and suffered from social, economic, and environmental instability. This had a long-standing influence on international and national tourism in the city and may have contributed to affect the activity on social media.

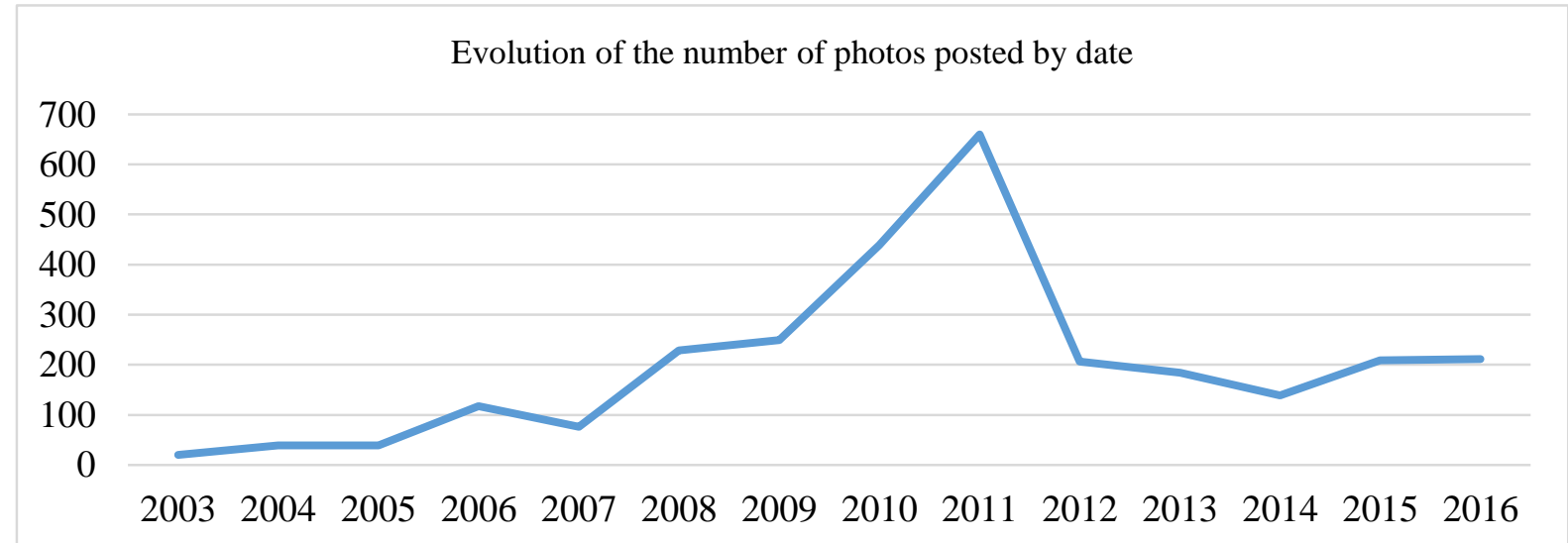

Fig. 3: Evolution of the number of photos posted on Flickr for Tripoli, Lebanon by date.

The processing of photos' geographical location data showed that the hotspots (places where more photos have been taken) in the city are the Mamluk Medieval core followed by the Ottoman square and part of its urban extension, Syria road (a red line that witnessed through history several sectarian conflicts), the international fair, and the fishery port (Fig. 4). The comparison between locals and tourists hot-maps (Fig. 4) reveals similarities in preferences as in both cases the hottest spot is the Mamluk core. However, locals also give value to other areas 
in the city like the international fair, Syria road, the northern part of the Abu Ali River, and the fisher port. The spatial distribution of photos differs among locals and tourists. Locals' photos are distributed all over the city and not in specific parts of it. They extend to areas that are not visited by tourists. We can differentiate important cold spots all along the coastline and between the hotspots resulting in an integrated mosaic of patches and corridors. This reading is not applicable to the tourists' heat map that is more concentrated and centered on the core of the city. When tourists are mainly interested in the historic and age values, locals do not only attribute value to the historic Mamluk core, but also to places related to their daily life practices and even to deteriorated landscapes that reflect the complex political and sectarian condition of the area.

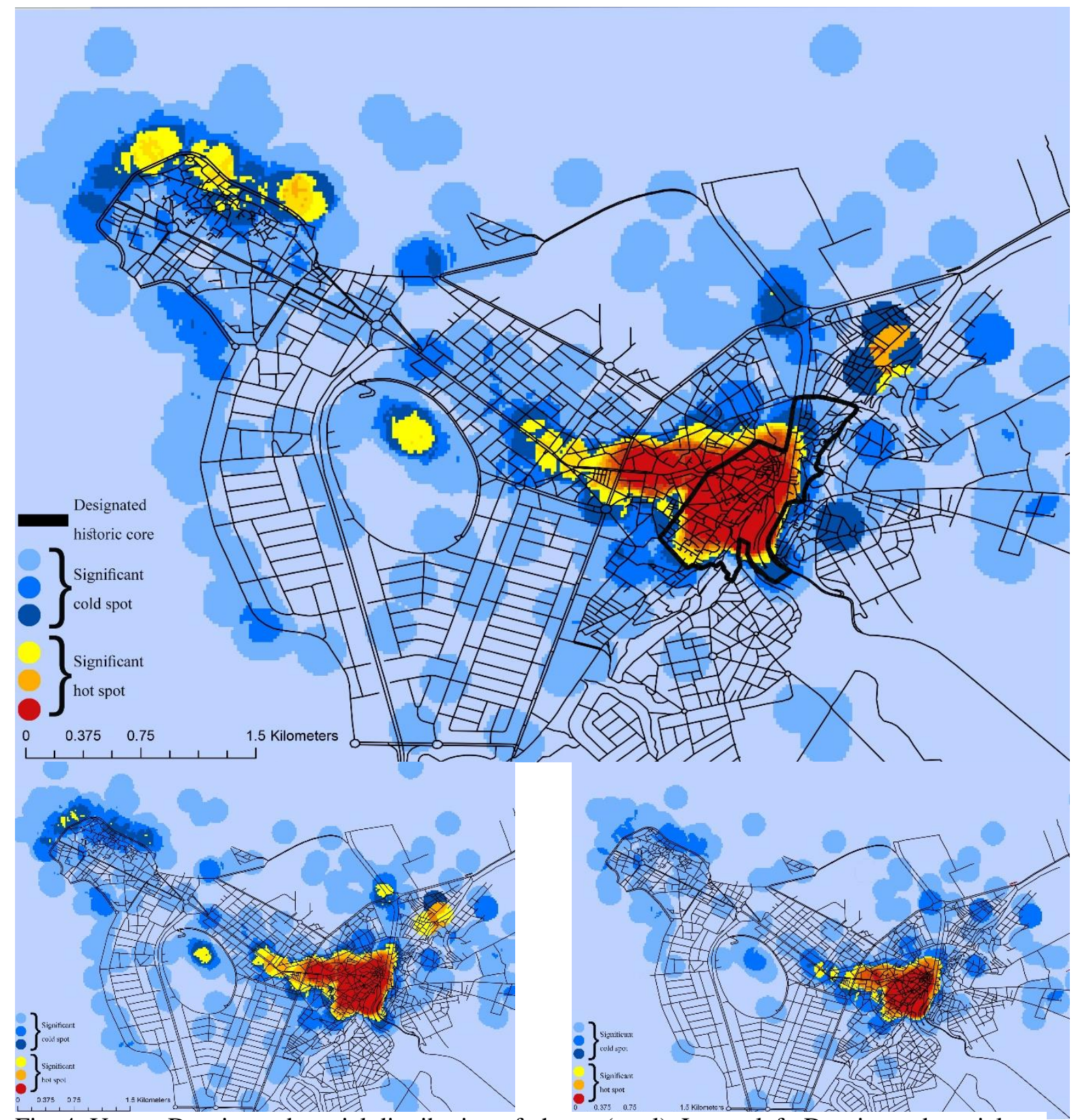

Fig. 4: Upper. Density and spatial distribution of photos (total). Lower left. Density and spatial distribution of photos (locals). Lower Right. Density and spatial distribution of photos (tourists). 


\subsection{Photos view scenes}

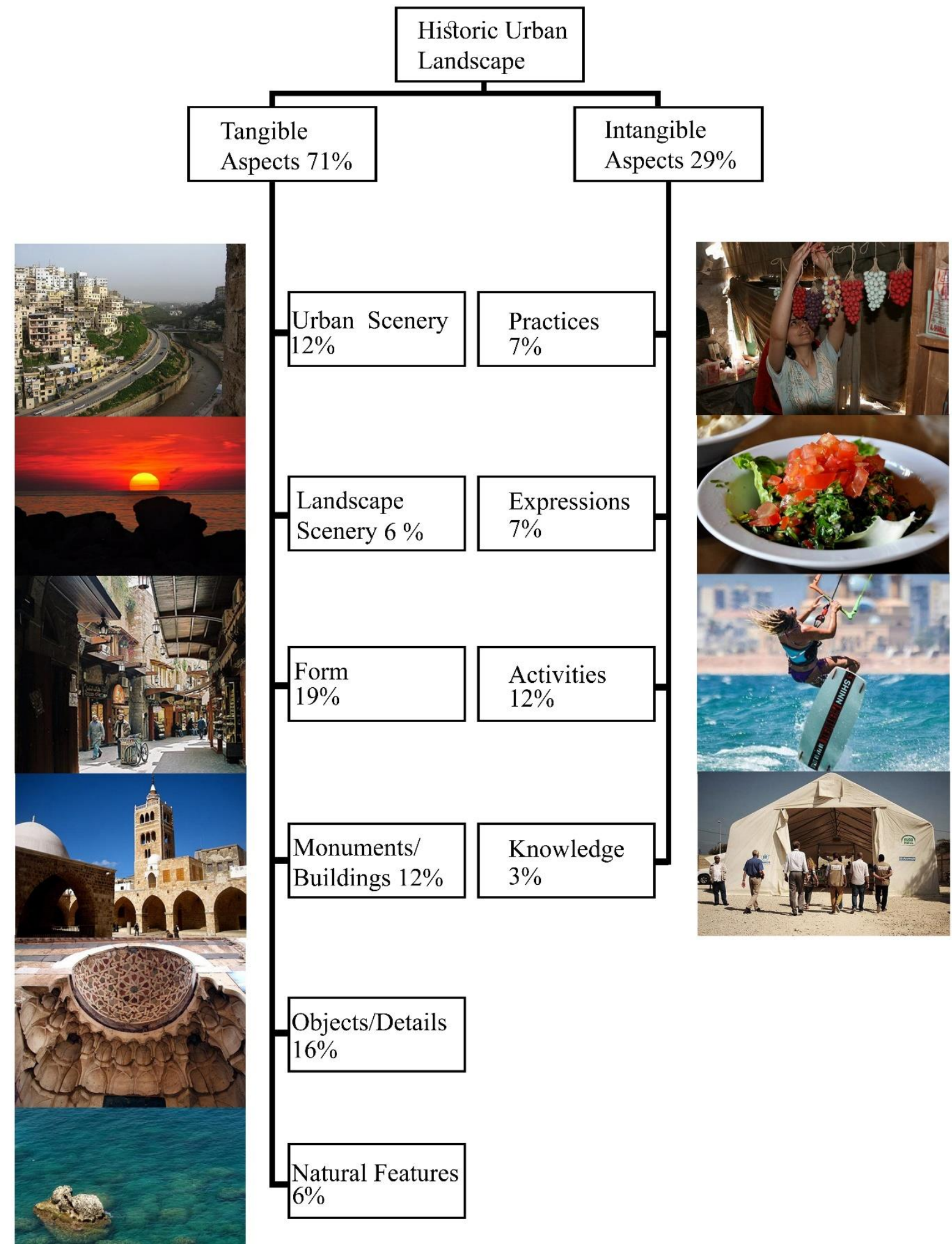

Fig. 5: Classification model of photos by view scenes. 
Within the historic urban landscape resides tangible and intangible attributes that define heritage significance, and the overall character of a city. The historic urban landscape includes the urban context with its natural and built features, perceptions and visual relationships, as well as socio-cultural practices and values, and the intangible dimension of heritage [6, para 9]. Our clustering of photos view scenes is an expert-based exclusive classification that represents the dominant feature of the scene. The results show that $71 \%$ of photos depict a tangible aspect of the city, whereas $29 \%$ of photos mainly depict an intangible aspect (Fig. 5). This outcome is of high value because it shows the plurality and diversity of heritage resources on the city level, and the multiple human-environment interactions operating across different scales.

Results reveal that the most photographed aspects are the commercial streets in the Mamluk core, the main monuments of the city, and architectural details, whereas the most posted urban scenery is that of the east side of the river in the Mamluk core. This part of the city does not fall within the demarcation of the classified historic core and is not indicated as a hotspot in the previous analysis. Almost all of these photos are taken from the citadel on the west bank of the river and are entitled (Fig. 6): view of Tripoli, Lebanon from the Citadel which lies high above the old town, view from the citadel... So the analysis of photos view scene reveals additional information and highlights sceneries that are not detected through the analysis of viewpoints geographical location.

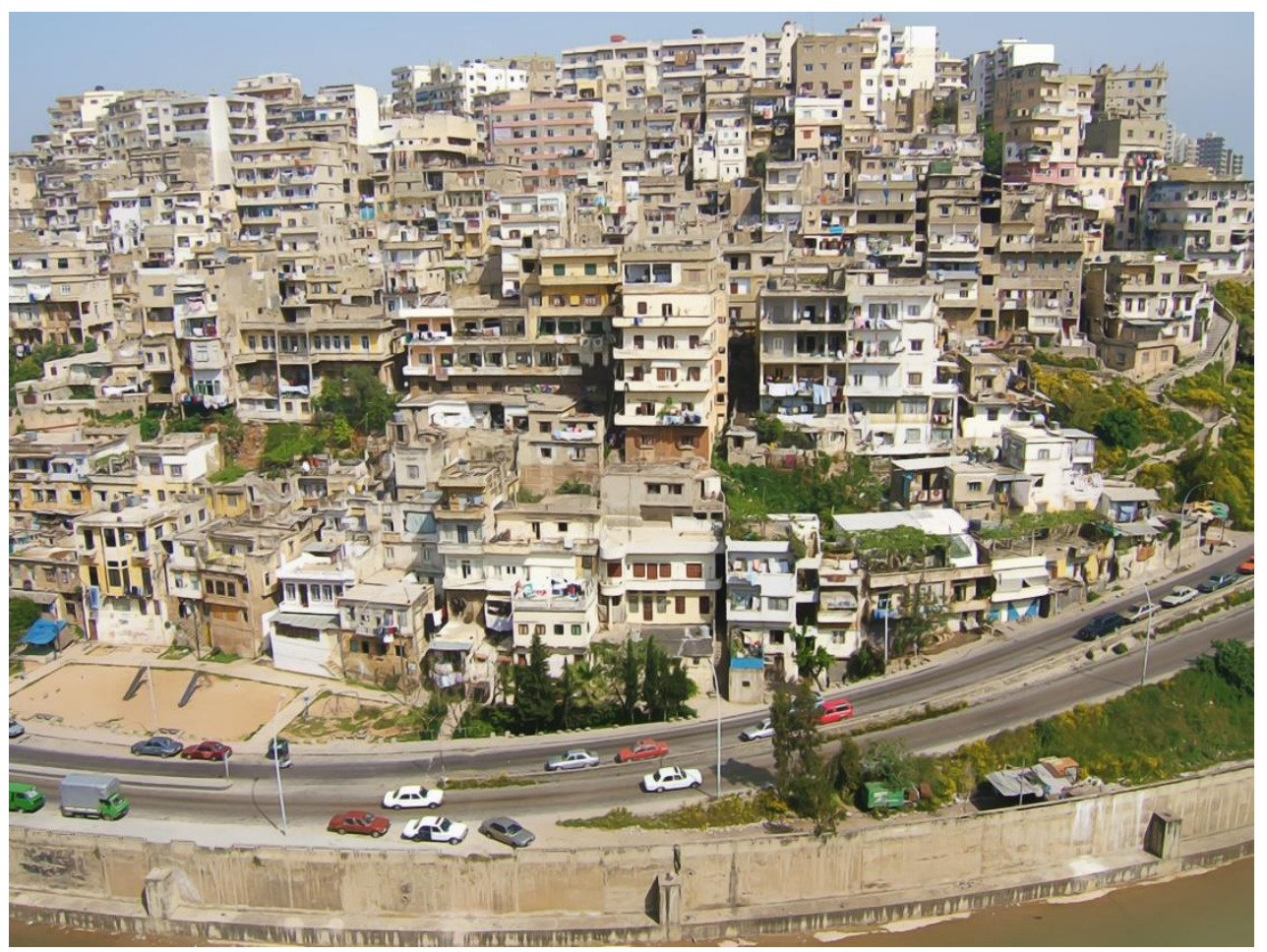

Fig. 6: View of Tripoli, Lebanon from the Citadel which lies high above the old town. James Holme. Flickr, 19/04/2006. 
Moreover, photos that depict people in their daily life like craftsmen, sellers, fishermen, kids playing on the street, women, and men feature distinctive characteristics of the city context and its socio-cultural assets, including the use of public space, gender dynamics in the public realm, traditions, customs, and religious-spiritual practices. For instance, there are photos for Sunday and Friday prayers, men claiming the public space mainly the sidewalks for social gathering, and women wearing a headscarf. Cultural expressions like gastronomy were also featured in many photos that show the traditional dishes and oriental sweets that the city is famous for.

\subsection{Tags}

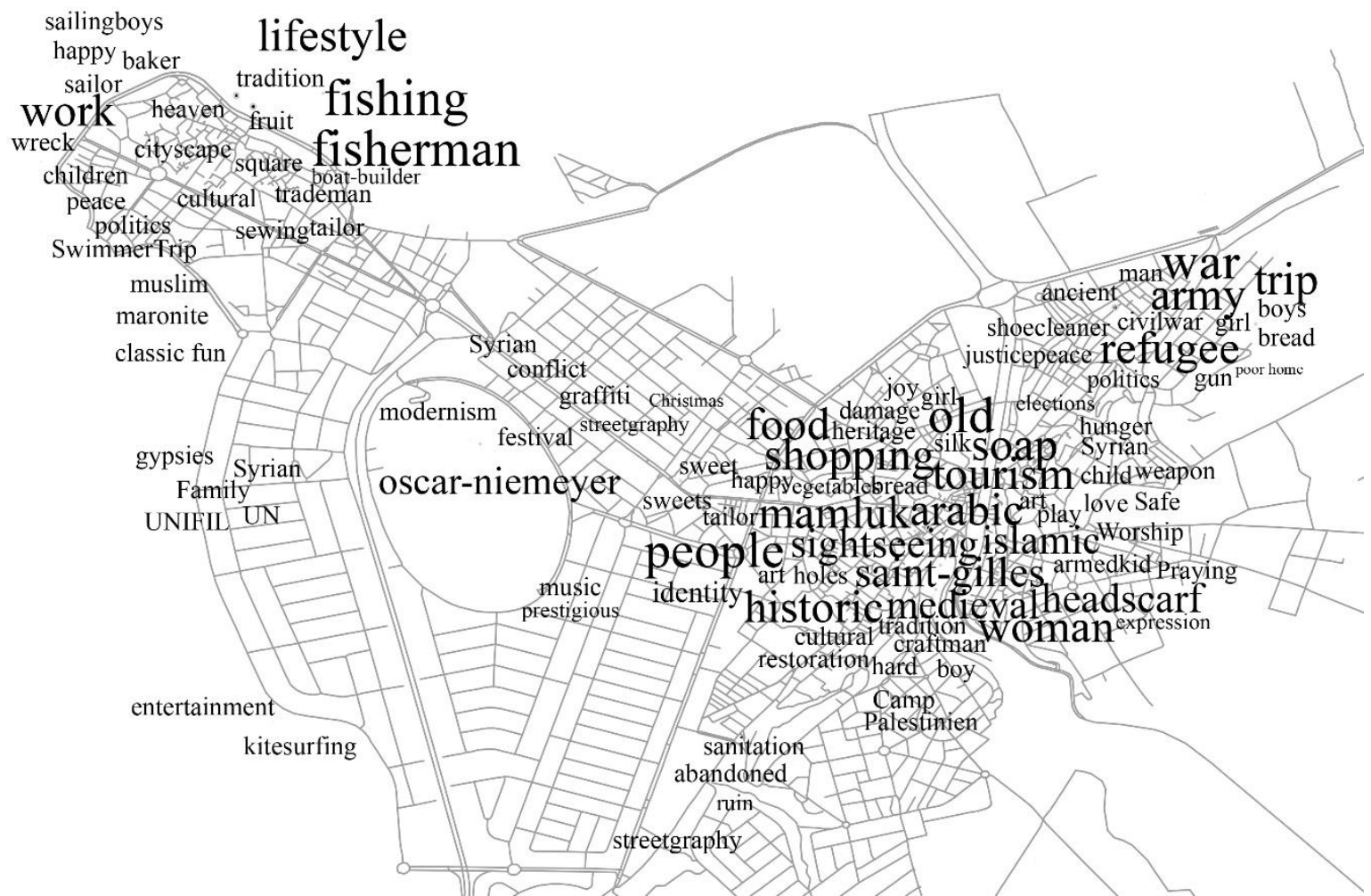

Fig. 7: Intangible tag clouds. The size of labels indicates the intensity of the perception.

The intangible tags clouds envisage what was labelled by the users as important aspects of the scenes through tagging photos (Fig. 7). The illustration enables us to connect the different parts of the city to their prevailing socio-economic and political conditions. It reflects the complexity of the city and its different interconnected layers. It highlights issues from the scale of the city to the scale of its smaller units. It shows as well how individuals' perception is not only shaped by the features of the built environment, but also by the unique expressions and intangible attributes and values residing in the different places of the city that contribute to its unique character. 
In the Mamluk core, photographers express their knowledge of the city's history and its different development eras. We can notice terms that embed historic age values like Mamluk, Medieval, Saint-Gilles, historic, and Old. They also use terms related to intangible attributes that convey shared spiritual expressions and social religious values like Arabic, Islamic, heritage, cultural, identity, tradition, praying, worship, and headscarf. Traditional craftsmanship also appears as part of the city's intangible heritage through notions like craftman, soap, and art. Another important reading comes from the labels that convey a message related to the existing socio-economic and political conditions in the conflict zone in the NorthEast, including war, refugee, army, politics, civil war, weapon, gun, poor, hunger, and hard. Minor messages calling for justice and peace can be noticed in this area as well. At the seafront, the focus shifts to sea life and practices like fishing, swimming, sailing, and surfing. Labels like lifestyle, heaven, happy, peace, and fun can be noticed. This outcome highlights the activities and feelings associated with this part of the city. We can also differentiate from the tags the location of the informal settlement on the seafront through associated tags like gypsies, Syrian, UN, and UNIFIL.

The comparison between locals' and tourists' vocabulary reveals that there are commonalities and differences in the understanding of urban heritage. The historical heritage and cultural expressions and activities are assets of high significance to locals and tourists. On the other hand, when tourists express interest in touristic activities, gastronomy, and people through notions like tourism, sightseeing, trip, festival, entertainment, food, sweets, bread, sailor, people, and children, locals also associate the physical environment with social, spiritual, and economic values.

These results show how semantics differ from one area to another within the city. We can easily distinguish the different daily-life conditions throughout the city, and we can start to understand its complexity and unique character through the intangible attributes. The tags express the interaction between photographers and the environment and the features that are influencing their perception. These tags include users' own vocabulary and reflect daily life practices, expressions and even concerns and conflictual values in relation to the existing political, religious, economic, and social conditions in the different parts of the city. These cultural expressions are part of people's heritage and collective identity. They extend the boundary of heritage in terms of definition and demarcation going beyond the so-called historic center and exceptional landscape to encounter all facets of the historic urban landscape at the city scale, and they highlight hidden heritage issues and places that are most of the time not 
considered by experts. These 'cold spots' are of unique capacity as they are representative of different heritage cultures, and they provide a space where controversial discourses about heritage, representativeness, legitimacy, and identity could unfold. Accordingly, a clear line of demarcation between 'cold' and 'hot' spots is not necessarily desirable in terms of heritage management. The relation between both types of places indeed allows multivocality and the incorporation of heritage concerns that are usually excluded from what is labelled as "official"/ "designated" heritage.
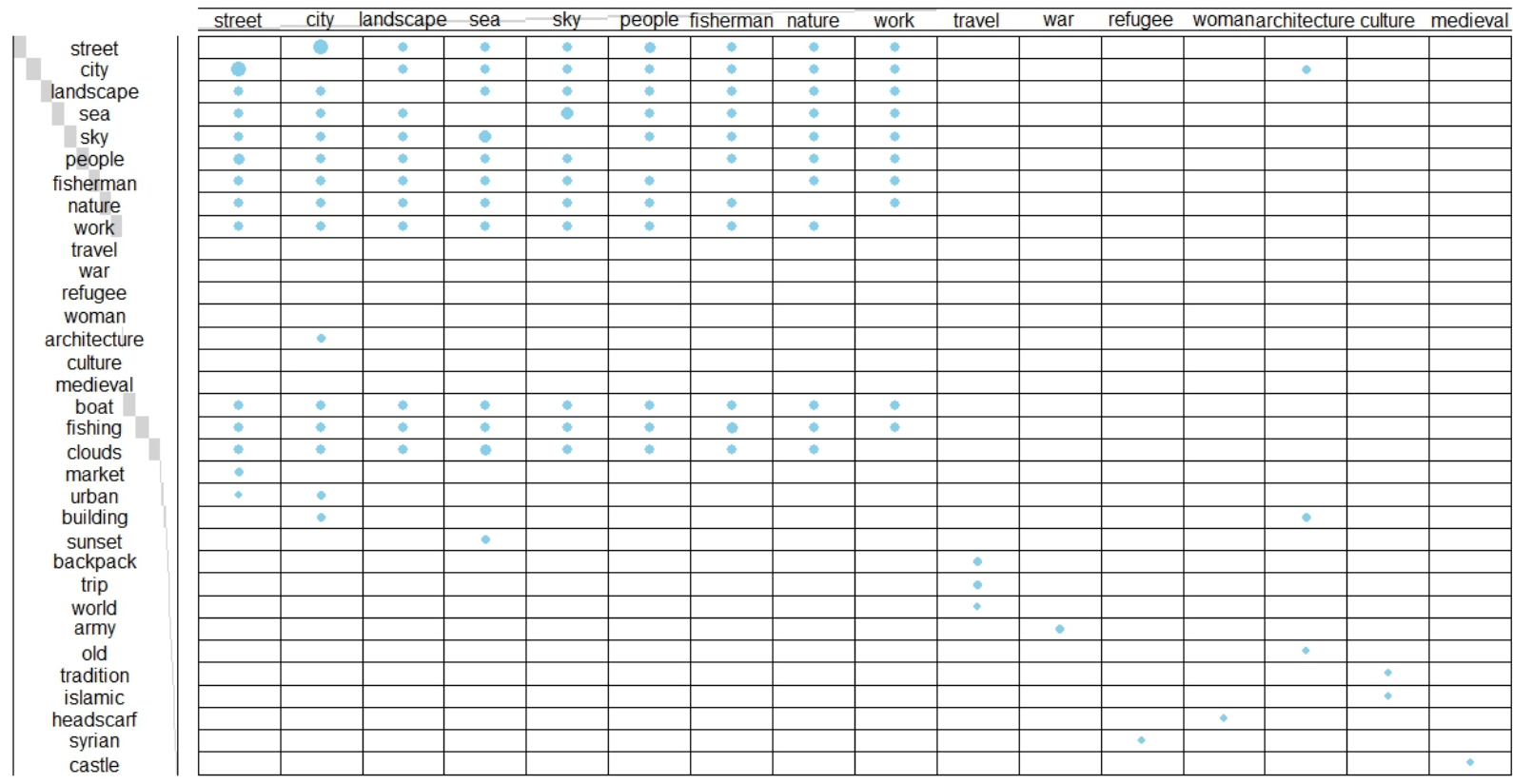

Fig. 8: Matrix showing the tags that are associated together more than 10 times.
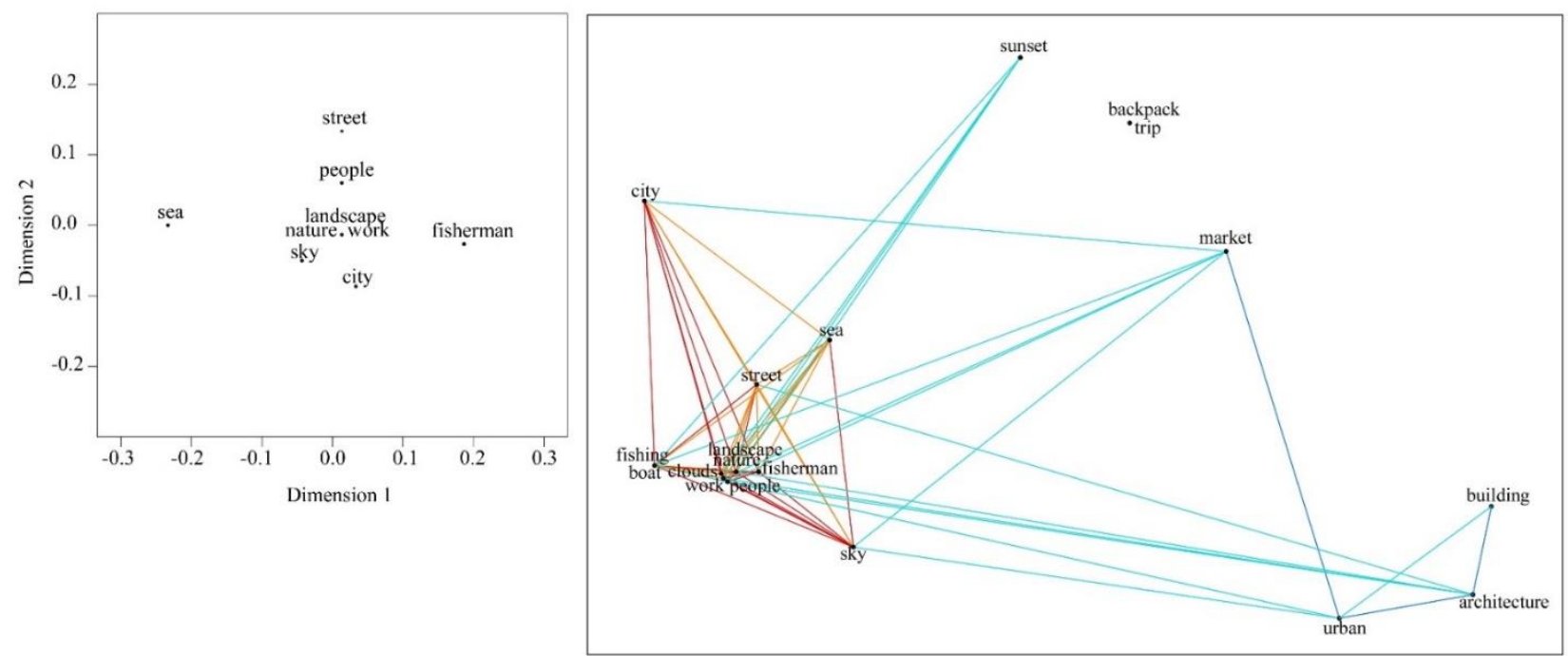

Fig. 9: Left panel. Two-dimensional semantic map of the nine nearest most frequent tag-sets. Right panel. Three-dimensional semantic map showing the distance between the most frequent tag-sets. 
Results from the analysis of tags semantics revealed an association between cultural and natural attributes in the city as well as tangible and intangible attributes (Fig. 8). This result is not in accordance with the exclusive classification model of photos' content since tags are more inclusive meaning a photo could have tags from different categories. For instance, we can notice a high level of association between tangible and intangible attributes including street, city, landscape, sea, sky, people, fisherman, nature, and work (Fig. 8 and 9). Photographers address the historic urban landscape as a coherent whole. They perceive it as a dynamic and interconnected entity. They do not focus on specific categories, instead, they blend and combine the tangible and intangible attributes as a whole. This outcome shows how users express ongoing interactions between place, people, expressions of lifeways, and practices with no paradigmatic rules. Another interesting result comes from the two-dimensional plot of nearest tag-sets. It shows that landscape, nature, and work are at the center of the semantic reading (Fig. 9) stressing one more time on the role of an important daily life practice which is work and on the city as a whole and on the interaction of nature and culture in shaping the character of the community.

An association between urban, building, and architecture can also be distinguished (Fig. 9). However, these are considered more as an aesthetic aspect and are not highly associated with other aspects of the city. Results show that in Tripoli the term culture is associated with terms like tradition and Islamic. Culture is reduced by photographers to its religious and custom-related dimensions. Furthermore, the political issues of the city like Syrian refugee and war are addressed in isolation from the other aspects of the city and are not linked to the urban context. They are separated semantically and spatially from their surrounding setting. The setting extends beyond the physical and visual aspects to comprise all sorts of interactions with the natural environment such as social, spiritual, and ecological that form the space and the dynamic cultural, social, and economic context [64].

\section{Discussion and Conclusion}

The methodology applied in this study for the analysis of data provided by Flickr improves our understanding of people-centered heritage in the context of exceptional and everyday landscape. Results showed that the different analyses complement one another to provide insights into every-day encounters with the historic urban landscape. When the analysis of photos' location showed the most popular vantage points in the city, that of the photos' view 
scenes revealed additional information on what the scenes actually depict, and finally, the analysis of tags highlighted the unique context-related characteristics, perceived heritage, and living heritage assets. These results have important implication for conservation practices as they question the limits of heritage areas and categories used for identifying values. They show that heritage assets are not only related to the historic core of the city but to a broader urban context, and that different places in the city have diverse heritage significance and are associated with cultural values that are context-specific and that do not necessarily fall into a categorical typology.

The results highlighted the multiple interests in respect to the exceptional and everyday landscape. It shed light on areas where heritage boundaries are challenged, and alternatives to dominant narratives of identity and nationalism can be articulated. These areas create liminal spaces, in which identities and cultural values are in continuous formation. These liminal spaces represent heterogeneity, multiculturalism, and diversity on the one hand and, on the other hand, they provide a platform (spatial and mental) that confronts tensions about the historic urban landscape. Liminal spaces should be considered in urban conservation practices to ensure inclusiveness and to balance diverse needs and interests.

In our case study, results revealed different landscape preferences and understandings of urban heritage among locals and tourists, as well as political and religious concerns in postconflict areas and related heritage significance that tend to be conflictual among the different areas in the city. The advantage behind the study of this semantics is that they can be used to make comparisons between users' and tourists' interpretation, use of vocabulary, and expressiveness in the characterization of the historic urban landscape. This comparison could provide useful information to experts as it allows them to integrate folksonomies generated from tagging into their classification models. This fact would allow a more inclusive and collaborative approach that could help to reach consensus on what cultural values to protect for future generations.

Our semantic analyses addressed only the tags data. However, Flickr provides additional data, like titles and descriptions that could reveal further information on users' comments to their uploaded images and values associated with the different scenes. Additionally, the analyzed data don't cover the demographic characteristic of users, including the age, gender, education, and professional status. Further research should improve methods comparison and develop new methods that consider the demographic characteristics of social 
media users as to relate the research data with that of the original population studied to highlight population biases and representativeness [65]. Accordingly, it is important to highlight that Flickr or any social media users do not represent the entire civic society, and that results from the analysis of social media data do not necessarily match with the general perception of the entire public realm. Instead, they provide the view of one stakeholder among many others in the city. Therefore, results should be complemented by outcomes from other survey methods like onsite questionnaire, workshops, and interviews. Results from these different surveys could match or diverge to suggest a more complex interpretation of user-environment relationship and heritage assets.

Moreover, Scholars and organizations tend to classify cultural values ascribed to heritage assets under different typologies, including aesthetic, social, historic, age, economic, political, scientific, and ecological values [66, 67]. A heritage asset could embed diverse values. However, this research showed that users do not necessarily refer to culture as the umbrella of other values or use the same mentality when ascribing values to heritage. Given the value-based heritage discourse, additional research effort could benefit from a deeper investigation on differences between experts and users interpretation of heritage values to inform future typologies of values system and to facilitate the communication discourse.

In conclusion, this study showed that the use of social media in the service of cultural heritage conservation provides additional knowledge on everyday encounters with the historic urban landscape and on heritage places and assets that are not covered by experts. Accordingly, complementing traditional survey methods with methods that rely on the use of social media would allow inclusiveness in the cultural heritage realm. The key challenge is to provide a comprehensive approach to combine results from different methods to support concrete applications and to inform decision making.

\section{Acknowledgements}

We thank our colleagues from Local Environment Management and Analysis (LEMA) Lab, namely Mario Cools and Ismail Saadi, who provided expertise in the statistical analysis that greatly assisted the research. 


\section{References}

[1] Council of Europe. (1975). The European charter of the Architectural heritage. Retrieved from http://www.icomos.org/en/charters-and-texts/179-articles-en-

francais/ressources/charters-and-standards/169-the-declaration-of-amsterdam (accessed 10 October 2017).

[2] Council of Europe. (1985). Convention for the Protection of the Architectural Heritage of Europe. Retrieved from

https://rm.coe.int/CoERMPublicCommonSearchServices/DisplayDCTMContent (accessed 10 October 2017).

[3] Council of Europe. (2000). European Landscape Convention. Retrieved from https://rm.coe.int/1680080621 (accessed 10 October 2017).

[4] UNESCO. (1976). Recommendation concerning the Safeguarding and Contemporary Role of Historic Areas. Retrieved from http://portal.unesco.org/en/ev.php-

URL_ID=13133\&URL_DO=DO_TOPIC\&URL_SECTION=201.html (accessed 5 June 2017).

[5] UNESCO. (2005a). Vienna Memorandum on "World Heritage and Contemporary Architecture - Managing the Historic Urban Landscape." UNESCO World Heritage Centre. Retrieved from http://whc.unesco.org/en/documents/5965 (accessed 5 June 2017).

[6] UNESCO. (2011). Recommendation on The Historic Urban Landscape. UNESCO World Heritage Center: Paris, France. Retrieved from http://www.stellenboschheritage.co.za/wpcontent/uploads/UNESCO-Historic-Urban-Landscapes-Recommendation-ShortNov2011.pdf (accessed 5 June 2017).

[7] Van Oers, R. (2007). Towards New International Guidelines For The Conservation of Historic Urban Landscapes(HUL). City \& Time, 3(3), pp. 43-51.

[8] Bandarin, F., \& Oers, R. van. (2012). The historic urban landscape: managing heritage in an urban century. Chichester, West Sussex, UK; Hoboken, NJ: Wiley Blackwell, chapter 4. [9] Veldpaus, L., Pereira Roders, A. R., \& Colenbrander, B. J. F. (2013). Urban Heritage: Putting the Past into the Future. The Historic Environment: Policy \& Practice, 4(1), pp. $3-$ 18.

[10] Van Oers, R. (2015). Conclusion. The Way Forward: An Agenda for Reconnecting the City. In F. Bandarin \& R. Van Oers (Eds.), Reconnecting the City: The Historic Urban Landscape Approach and the Future of Urban Heritage (pp. 317-329). United Kingdom: John Wiley \& Sons.

[11] Malpas, J. (2007). Cultural heritage in the age of new media. In Y. E. Kalay, T. Kvan, \& J. Affleck (Eds.), New Heritage: New Media and Cultural Heritage, London and New York: Routledge, pp. 13-26.

[12] Russo, A., Watkins, J., Kelly, L., \& Chan, S. (2008). Participatory Communication with Social Media. Curator: The Museum Journal, 51(1), pp. 21-31.

[13] Garduño Freeman, C. (2010). Photosharing on Flickr: intangible heritage and emergent publics. International Journal of Heritage Studies, 16(4-5), pp. 352-368.

[14] Terras, M. (2011). The Digital Wunderkammer: Flickr as a Platform for Amateur Cultural and Heritage Content, Library Trends, Special Issue on Involving Users in The CoConstruction of Digital Knowledge In Libraries, Archives, and Museums, 59(4), pp. 686706.

[15] Ciolfi, L. (2012). Connecting to everyday practices: experiences from the digital natives exhibition. In Giaccardi, E (Eds.), Heritage and social media, London and New York, Routldege, pp. 69-86.

[16] Giaccardi, E. (2012). Reframing heritage in a participatory culture. In Giaccardi, E (Eds.), Heritage and social media, London and New York, Routldege, pp. 1-10. 
[17] Liew, C. L. (2014). Participatory Cultural Heritage: A Tale of Two Institutions' Use of Social Media. D-Lib Magazine, 20 (3/4).

[18] Iversen, O. S., \& Smith, R. C. (2012). Connecting to Everyday Practices: Experiences from the Digital Natives Exhibition. In Giaccardi, E (Eds.), Heritage and social media, London and New York, Routldege, pp.126-144.

[19] Silberman, N., \& Purser, M. (2012). Collective Memory as Affirmation: PeopleCentered Cultural Heritage in a Digital Age. In Giaccardi, E (Eds.), Heritage and Social Media, London and New York, Routledge, pp. 13-39.

[20] Taylor, J., \& Gibson, L. K. (2017). Digitisation, digital interaction and social media: embedded barriers to democratic heritage. International Journal of Heritage Studies, 23(5), pp. 408-420.

[21] UN-HABITAT. (2016). HABITAT III. The New Urban Agenda, SDG 11, Target 11.4. Quito. Retrieved from http://habitat3.org/the-new-urban-agenda/

[22] UN-HABITAT. (2017). Action Framework for Implementation of the New Urban Agenda (AFINUA). Retrieved from http://nua.unhabitat.org/list1.htm\#

[23] Girardin, F., Vaccari, A., Gerber, A., Biderman, A., \& Ratti, C. (2009). Quantifying urban attractiveness from the distribution and density of digital footprints. International Journal of Spatial Data Infrastructures Research, 4, pp. 175-200.

[24] Frias-Martinez, V., Soto, V., Hohwald, H., \& Frias-Martinez, E. (2012). Characterizing Urban Landscapes Using Geolocated Tweets. In International Conference on Social Computing (SocialCom), Amsterdam: IEEE, pp. 239-248.

[25] Stefanidis, A., Crooks, A., \& Radzikowski, J. (2013). Harvesting ambient geospatial information from social media feeds. GeoJournal, 78(2), pp. 319-338.

[26] Brown, G., Weber, D., \& de Bie, K. (2014). Assessing the value of public lands using public participation GIS (PPGIS) and social landscape metrics. Applied Geography, 53, pp. 77-89.

[27] Dunkel, A. (2015). Visualizing the perceived environment using crowdsourced photo geodata. Landscape and Urban Planning, 142, 173-186.

[28] García-Palomares, J. C., Gutiérrez, J., \& Mínguez, C. (2015). Identification of tourist hot spots based on social networks: A comparative analysis of European metropolises using photo-sharing services and GIS. Applied Geography, 63(Supplement C), pp. 408-417.

[29] Zanten, B. T. van, Berkel, D. B. V., Meentemeyer, R. K., Smith, J. W., Tieskens, K. F., $\&$ Verburg, P. H. (2016). Continental-scale quantification of landscape values using social media data. Proceedings of the National Academy of Sciences, 113(46), pp. 12974-12979.

[30] Shoval, N., \& Ahas, R. (2016). The use of tracking technologies in tourism research: the first decade. Tourism Geographies, 18(5), 587-606.

https://doi.org/10.1080/14616688.2016.1214977

[31] McKercher, B., Shoval, N., Ng, E., \& Birenboim, A. (2012). First and Repeat Visitor Behaviour: GPS Tracking and GIS Analysis in Hong Kong. Tourism Geographies, 14(1), 147-161. https://doi.org/10.1080/14616688.2011.598542

[32] Pettersson, R., \& Zillinger, M. (2011). Time and Space in Event Behaviour: Tracking Visitors by GPS. Tourism Geographies, 13(1), 1-20. https://doi.org/10.1080/14616688.2010.529932

[33] De Cantis, S., Ferrante, M., Kahani, A., \& Shoval, N. (2016). Cruise passengers' behavior at the destination: Investigation using GPS technology. Tourism Management, 52, 133-150. https://doi.org/10.1016/j.tourman.2015.06.018

[34] Ames, M., \& Naaman, M. (2007). Why we tag: motivations for annotation in mobile and online media (p. 971). Proceedings of the SIGCHI Conference on Human Factors in Computing Systems, California, USA, pp. 971-980. 
[35] Nov, O., Naaman, M., \& Ye, C. (2008). What drives content tagging: the case of photos on Flickr. In proceeding of the $26^{\text {th }}$ annual SIGCHI conference on human factors in computing systems, ACM, New York, USA, pp. 1097-1100.

[36] Sigurbjörnsson, B., \& van Zwol, R. (2008). Flickr tag recommendation based on collective knowledge. In Proceeding of ACM International World Wide Web Conference, New York, USA, ACM, pp. 327-336.

[37] Davis, M., Smith, M., Stentiford, F., Bamidele, A., Canny, J., Good, N., ... Janakiraman, R. (2006). Using context and similarity for face and location identification. In Proceedings of the IS\&T/SPIE 18th Annual Symposium on Electronic Imaging Science and Technology. [38] Kennedy, L., Chang, S.-F., \& Kozintsev, I. V. (2006). To search or to label?: predicting the performance of search-based automatic image classifiers. In proceeding of the $8^{\text {th }} A C M$ international workshop on multimedia information retrieval, ACM, New York, USA, pp. 249-258.

[39] Rattenbury, T., \& Naaman, M. (2009). Methods for extracting place semantics from Flickr tags. ACM Transactions on the Web, 3(1), pp. 1-30.

[40] Tamara L. Berg, \& D. A., Forsyth. (2007). Automatic Ranking of Iconic Image. Technical report, EECS Department, University of California, Berkeley.

[41] Kennedy, L., Naaman, M., Ahern, S., Nair, R., \& Rattenbury, T. (2007). How flickr helps us make sense of the world: context and content in community-contributed media collections. In proceedings of the $15^{\text {th }}$ international conference on Multimedia, Augsburg, Germany, pp. 631-640.

[42] Economou. (2015). Heritage in the Digital Age. In W. Logan, M. N. Craith, \& U. Kockel (Eds.), A Companion to Heritage Studies. John Wiley \& Sons.

[43] Wicks, S. P. (2015). The value of mobile phone applications in heritage interpretation. Masters by Research in Cultural Heritage. University of Birmingham, Ironbridge International Institute for Cultural Heritage. Retrieved from http://etheses.bham.ac.uk/6048/ [44] Stiller, D., \& Beex, W. F. (2017). Apps under the surface. Problems with Cultural Heritage apps. Studies in Digital Heritage, 1(2), 326-343. https://doi.org/10.14434/sdh.v1i2.23232

[45] Van House, N. (2007). Flickr and public image-sharing: Distant closeness and photo exhibition. In CHI '07 Extended Abstracts on Human Factors in Computing Systems (pp. 2717-2722). New York: ACM Press.

[46] Trant, J. (2009). Studying Social Tagging and Folksonomy: A Review and Framework. Journal of Digital Information, Special Issue on Digital Libraries and User-Generated Content, 10(1).

[47] Halbwachs, M. (1997). La Mémoire collective. Edition critique établie par Gérard Namer, préface de Marie Jaisson. Paris: Albin Michel, p., 132 FF [1 ${ }^{\mathrm{er}}$ éd. 1950].

[48] Páez, D., \& Liu, J. (2011). Collective memory of conflicts. In Bar-Tal, D (Eds.), Intergroup Conflicts and Their Resolution: A Social Psychological Perspective, New York, Psychology Press, pp. 105-124.

[49] Misztal, B. A. (2010). Collective Memory in a Global Age: Learning How and What to Remember. Current Sociology, 58(1), pp. 24-44.

[50] O'Donnell, P., \& Turner, M. (2012). The Historic Urban Landscape Recommendation: A New UNESCO Tool for a Sustainable Future. IFLA, Cape Town.

[51] Kleymeyer, C. D. (1994). Introduction. In Kleymeyer, C. D. (Eds.), Cultural Expression and Grassroots Development: Cases from Latin America and the Caribbean. Lynne Rienner Publishers, pp. 1-14.

[52] UNESCO. (2005). The Convention on the Protection and Promotion of the Diversity of Cultural Expressions. Paris, France. Retrieved from

https://en.unesco.org/creativity/convention (accessed 20 November 2017). 
[53] UNESCO. (2016). The Historic Urban Landscape Guidebook: Managing heritage in dynamic and constantly changing urban environments. Retrieved from http://www.hulballarat.org.au/resources/HUL\%20Guidebook_2016_FINALWEB.pdf (accessed 20 November 2017).

[54] Friedman, T. (2016). The changing political economy of globalization: Multilateral institutions and the 2030 Agenda. Presented at the The joint meeting of United Nations Economic and Social Council (ECOSOC) and the Second Committee of the UN General Assembly, United Nations.

[55] ICCROM. (2015). Promoting People-Centred Approaches to Conservation: Living Heritage. Retrieved December 8, 2017, from http://www.iccrom.org/priority-areas/livingheritage/

[56] UNESCO. (2016). Culture: urban future: global report on culture for sustainable urban development. Paris, France. Retrieved from

http://unesdoc.unesco.org/images/0024/002462/246291E.pdf (accessed 10 August 2018).

[57] Sen, A. (2007). Identity and Violence: The Illusion of Destiny (Reprint edition). New York, NY: W. W. Norton \& Company.

[58] Rautenberg, M. (1998). L'émergence patrimoniale de l'ethnologie : entre mémoire et politiques publiques. In Poulot, D (Eds.), Patrimoine et Modernité. Paris L'Harmattan, pp. 279-291.

[59] Tweed, C., \& Sutherland, M. (2007). Built cultural heritage and sustainable urban development. Landscape and Urban Planning, 83(1), pp. 62-69.

[60] Sessions, C., Wood, S. A., Rabotyagov, S., \& Fisher, D. M. (2016). Measuring recreational visitation at U.S. National Parks with crowd-sourced photographs. Journal of Environmental Management, 183, 703-711. https://doi.org/10.1016/j.jenvman.2016.09.018 [61] Tenkanen, H., Di Minin, E., Heikinheimo, V., Hausmann, A., Herbst, M., Kajala, L., \& Toivonen, T. (2017). Instagram, Flickr, or Twitter: Assessing the usability of social media data for visitor monitoring in protected areas. Scientific Reports, 7(1), 17615. https://doi.org/10.1038/s41598-017-18007-4

[62] McHarg, I. L. (1969). Design with nature. Published for the American Museum of Natural History Press.

[63] UNDP. (2017). Special peace Building in Lebanon phase 3: Strengthening Tripoli social cohesions (p. 38). Lebanon: United Ntaions Development Programme (UNDP).Retrieved from

http://www.lb.undp.org/content/dam/lebanon/docs/CrisisPreventionRecovery/Publications/Si gned\%20PD\%20-\%20Tripoli\%20Social\%20Cohesion.pdf (accessed 10 August 2018).

[64] ICOMOS. (2005). Xi'an Declaration on the conservation and setting of heritage structures sites and areas. 15th General Assembly of ICOMOS. X'ian, China. Retrieved from http://www.international.icomos.org/xian2005/xian-declaration.pdf (accessed 5 August 2018).

[65] Ruths, D., \& Pfeffer, J. (2014). Social media for large studies of behavior. Science, 346(6213), 1063-1064. https://doi.org/10.1126/science.346.6213.1063

[66] ICOMOS. (2013). The Australia ICOMOS Charter for Places of Cultural Significance (Burra Charter). Retrieved December 8, 2017, from http://australia.icomos.org/wpcontent/uploads/The-Burra-Charter-2013-Adopted-31.10.2013.pdf (accessed 10 November 2017).

[67] Tarrafa Silva, A. \&Pereira Roders, A. (2012). Cultural heritage management and heritage (impact) assessments. Proceedings of the Joint CIB W070, W092 \& TG72 International Conference on Facilities Management, Procurement Systems and Public Private Partnership, Cape Town. 